\title{
A Concept Analysis in relation to the Cultural Competency of the Palliative Care Workforce in Meeting the Needs of Young People from South Asian Cultures
}

Brown, E., Coad, J. \& Franklin, A. 


\section{A Concept Analysis in relation to the Cultural Competency of the Palliative Care Workforce in Meeting the Needs of Young People from South Asian Cultures}

\section{Abstract}

Although recent UK and European health and social care policy and legislation has expressed a commitment towards making services equitable and accessible to families from BAME cultures, it is apparent that members of South Asian communities may be particularly vulnerable to inequalities in respect of palliative care. The paper clarifies the meanings of cultural competency and identifies within nursing and health-related literature how the cultural competency of the palliative care workforce impacts on the holistic care of young people with life-limiting or life-threatening conditions from South Asian cultures. The paper concludes the concept of cultural competency is complex, multi-faceted and often expressed ambiguously. There is an urgent need to develop a robust tool to assess cultural competency in practice so that the concept is understood as universally integral to healthcare, irrespective of a person's race or ethnicity.

Keywords: concept analysis; young people; life-limiting conditions South Asian cultures; cultural competency; palliative care workforce.

\section{Introduction}

Many young people diagnosed with life-limiting or life-threatening conditions are living longer resulting in immense challenges for service providers (Together for Short Lives (TFSL)/Marie Curie Cancer Care (MCCC) 2012, Fraser et al. 2012). In 2010 the prevalence of life-limiting conditions in under-19s was 32 in 10,000. The greatest increase in UK numbers was in young people over 19 years of age estimated at 34 in 10,000 (Fraser 2012). The palliative needs of these young people are unique, often complex and constantly change (TFSL and MCCC 2012 Brown et al. 2013). Therefore it is important that care is focused on individual needs. According to Berntsson et al. (2007) this care should enable young people, whenever possible, to make informed choices in respect of their care, including cultural preferences. 


\section{Background}

The term Black, Asian Minority Ethnic (BAME) is increasingly used when referring to people other than the indigenous population of the United Kingdom (Institute for Race Relations 2015). The 2011 census estimated that the BAME population of England and Wales was eight million, representing $14.1 \%$ of the overall population (Office for National Statistics 2012).

A proportion of BAME people are South Asian (Indian, Pakistani, and Bangladeshi) where consanguinity or intermarriage is particularly common. In these circumstances there is an enhanced risk of congenital abnormalities and life-threatening or life-limiting conditions owing to parents sharing common genetic material (Manchaiah et al. 2011).

Ethnicity and culture affect the ways in which people understand and experience health, illness, suffering and bereavement (Kofman \& Lukes 2012, Brown et al. 2013). Baggerley \& Abugideiri (2010) suggest that in some South Asian communities, palliative care may be perceived as 'giving up hope' and in the case of families with children, that parents have neglected to 'protect' their child.

Carter et al. (2012), argue that the provision of healthcare for people from BAME groups may be used as a measure of 'good' healthcare services for the population in general. There is a growing literature available on children who have life-limiting or life-threatening conditions. However, literature which captures the voices and experiences of children from BAME cultures is largely absent, a situation that appears to have remained unchanged since it was highlighted by Butt \& Mirza (1996) and Shah (1995). Where research has been undertaken this has primarily focused on young people with cancers from majority rather than minority ethnic groups (Ali et al. 2001, Together for Short Lives and Marie Curie Cancer Care 2012). Equalities National Council and Scope 2012).

\section{Background to concept analysis}


There are a variety of approaches to concept analysis which are largely determined by the aim of the analysis (Rodgers \& Knafl 2000). Walker \& Avant's (2011) approach, regards a concept as an 'entity' or a 'thing' (e.g. a mental image or an idea) regardless of the context or changing circumstances, an approach which has been criticised by Baldwin \& Rose (2009) as 'simplistic'. According to Rodgers (1989), an evolutionary view is needed which acknowledges that concepts are continually subjected to change and influenced by 'significance', 'use' and 'application' to practice. Rodger's (1989) evolutionary approach is based on the philosophy that concepts change or evolve over time and that they are affected by the context in which they are occurring. Rodgers (1989) does not however purport that her model provides a definitive approach to defining a concept. Rather, she recommends that analysis provides an indication about where further development of the concept is needed. Coad (2002) undertaking a concept analysis of the Nurse Lecturer, based her framework on Rodger's (1989) model, using a six step approach (Table 1).

In Wilson's (1969) view, the principal aim of concept analysis is to provide structure, clear rationale and meaning to thinking. Indeed, Coad (2002) drawing on the work of Wilson (1969) cautions that without a 'framework and purposiveness', thinking might otherwise meander indefinitely. p.102.

The concept analysis in this paper builds on Coad's (2002) adapted framework.

\section{Aim}

The aim is: a) to clarify the meaning of cultural competency and, b) to identify within the literature how the cultural competency of the palliative care workforce impacts on the holistic care of young people with life-limiting or life-threatening conditions from South Asian cultures.

\section{Data Sources}


A preliminary search of the literature revealed a large number of synonyms for the words 'culture', 'ethnicity', 'faith' and ' South Asian religion' and these have informed the choice of key words.

National and International data bases were searched including Scopus, MEDLINE, CINAHL, Science Direct, PubMed. An initial search of MEDLINE was undertaken using the key words. Limiters were set to the key words being included in either the paper title or abstract, published in English language 1990-2015. Historical work prior to 1990 was also referred to when appropriate. The MEDLINE search identified 1543 references, most of which were narrative accounts rather than empirical studies. Including the other data bases, acquired a further 34 references with a further 28 citations located in article reference lists. 22 duplicate papers were removed and as Rodgers (1989) suggests, inclusion and exclusion criteria were applied to the total number of papers before finally selecting twenty per cent. A total of 38 papers were read and evaluated in entirety. (See Table 2)

While reading the articles, key words and themes were highlighted and entered onto a matrix. Thematic analysis was undertaken for each column heading. Notes were also made in relation to general findings.

\section{Results}

\section{Identify and name the concept of interest - Culturally-Competent Care}

The focus of this concept analysis on 'culturally-competent care' is a construct of the words 'culture', 'competency' and 'care'. Therefore the starting point is a) an exploration of the meaning(s) attributed to the term 'culture' followed by b) analysis of the construct, 'culturallycompetent care.'

\section{The concept of culture}

The concept of 'culture' generally lacks clarity among models and theories of nursing and healthcare (George 2011). Indeed, George (2011) maintains that despite numerous and varying attempts to define culture, the task has remained both difficult and challenging for 
three reasons. First, there are diverse and divergent opinions about the meaning of 'culture'. Second, the construct is complex because of its subjective and personal nature. Finally, culture and ethnicity are often used interchangeably, further complicating a definition, for example Lubimir \& Wen (2011) refer to 'ethnic heritage'. p. 239. Ethnicity is a fluid term that refers to identity, culture and belonging as well as to religion, nationality and geography. Broad categories of ethnic identity used in surveys often neglect to determine subtle differences between communities and there is no standard way of defining ethnicity and this may explain the lack of robust data in relation to the numbers of children and young people with palliative care needs from BAME cultures.

Parekh (2005) writing from a political viewpoint describes 'culture as lacking a coherent philosophical statement of its central principles'. p.46. Parekh (2005) goes on to cite Archer (1985) 'culture has displayed the weakest development of any key concept' (p.14).

Different disciplines have their own distinct definitions and conceptualizations of culture. Terminology used in the literature to refer to people from BAME groups remains inconsistent (Chand \& Thoburn 2010, Brown et al. 2013). Terms include: Black families, non-White families, minority ethnic families, non-indigenous families, ethnic families, and on occasions, permutations of these terms. Furthermore there are numerous references in the literature distinguishing people by place of birth or ancestry such as Indian, Pakistani, and Bangladeshi and to faith, for example, Muslim, Hindu, and Sikh. A review of ten dictionary or thesaurus definitions of the word 'culture' in relation to the disciplines of medicine, healthcare, nursing and social work has revealed the only common words to all sources were 'groups', 'communities' or 'organisations'. While it could be expected that disciplines would place emphasis on concepts which are of particular relevance to their policy and practice, the lack of shared definitions is surprising.

Much of the literature refers to the process of change that occurs when different cultural groups come into continuous contact with a host culture as 'acculturation'. Taylor (2003) is 
of the opinion that although change occurs in both groups, there is likely to be greater change within the acculturating group than in the host group, including attitudes, lifestyle and behaviour and that change will occur collectively and individually as people adapt to a new society.

Most of the acculturation literature has focused on adults and there is paucity of empirical evidence about how young people from South Asian cultures view their cultural identity (Robinson 2008). Where research has been undertaken, Robinson (2008) concludes that most young people from South Asian cultures express a wish towards retaining their cultural heritage, family cohesion and language, often in an adapted form.

\section{Culturally-competent care}

No single definition of 'culturally-competent care' could be found in the literature. Definitions generally refer to knowledge, attitudes and skills that enable practitioners to comprehend and appreciate cultural differences, and to the ability to provide appropriate healthcare which takes into account and responds to, people's attitudes, feelings, cultural beliefs and circumstances.

Tucker et al. (2013) describes culture as rooted in an individual's identity and therefore the construct 'culturally-competent care' demands 'a commitment to preserving the dignity of the client by preserving their culture.' p.39. Harriss \& Salway (2009) argue that in BAME communities the immediate family is the primary resource for managing the impact of longterm ill-health and disability. Owens and Randhawa (2004) however caution against stereotyping families and failing to recognise the diversity of family structures within South Asian communities.

Organizations often recognize the challenge presented by the health care needs of people from different ethnic communities, each with their own cultural characteristics (Beach et al. 2005). Cultural competency is pivotal to reducing health inequalities and improving access to high-quality healthcare that is respectful of, and responsive to, the unique needs of each 
patient and their family (Tucker et al. 2013). McWhinney (1989) extends this viewpoint, writing about care which 'should address both the patient's and the physician's agenda'. (p.27).

Literature has increasingly reported a need for healthcare workers to develop care matched to a person's cultural needs (Helman 2000, Barzansky et al. 2000). There appears however to be an assumption on behalf of many authors that healthcare professionals have a preexisting comprehension of the concept of 'cultural care' and therefore, in practice, they possess the knowledge and skills to build effective relationships with patients, (Owens \& Randhawa 2004, Beach et al. 2005). However, 'cultural competency' surpasses cultural knowledge. It demands that the healthcare system is inclusive of diverse world views in developing, implementing and evaluating healthcare. (Johnson et al. 2013).

A number of studies have evaluated tools designed to increase the cultural competency of nurses and health professionals. However, although many of these tools provide a framework against which the cultural competency of healthcare professionals is evaluated, there remain very few definitions of what is being assessed. According to Kumas-Tan et al. (2007) and Constantine \& Ladany (2001) measures of cultural competence used by healthcare professionals largely disregard the 'power relations' of social inequality, assuming that the acquisition of knowledge and the development of skills by healthcare professionals will result in positive change in practice and an understanding of cultural behaviour. These authors argue that rather than using knowledge as a benchmark for assessing cultural competence, measures need to be taken to assess the quality of practice, based on how professional skills and attitudes impact on the quality of patient experience. Furthermore they contend that existing measures of professional cultural competence have often been developed by people of White middle class ethnicity without involving service-users.

Fazil et al. (2004) suggest that services should be 'family-centred' and also 'communityorientated'. p.396. These authors make a plea for professionals to be recruited from within 
the communities of service users, in order for them to advocate on their behalf in ways that represent their views and experiences. Where such a model of recruitment is practiced, the numbers of families from South Asian families accessing palliative care services is increasing year on year (Brown 2007, Taylor et al. 2010).

\section{Identify surrogate terms and related uses of the concept 'culturally-competent care'.}

Searching for associated attributes or clusters of characteristics related to a concept have been recognized as a valid and essential undertaking in concept analysis (Rodgers 1989). Examples of surrogate terms in the literature in relation to culturally-competent care are illustrated in Table 3.

\section{Identify the attributes related to the concept}

From an evolutionary viewpoint a concept is regarded as an abstraction associated with attributes or distinctive characteristics (EunYoung 2004). The literature frequently discusses the importance of the professional's attitudes and values in achieving culturally- competent care. However, as Taylor (2003) argues, medical school curricula has traditionally focused on providing information about minority communities, emphasising 'difference' from a stereotypical viewpoint, rather than developing skills in communicating with people in order to understand their expressed needs.

The importance of good communication between healthcare professionals and patients is well documented (Department of Health 2008, Hutchinson 2011, Street et al. 2011). Chamba \& Jones (2000) argue that effective communication requires 'insight into the cultural and service context in which conversations take place' (p.92). EunYoung (2004) makes a plea for professionals to demonstrate 'openness' to cultural diversity, being non-judgemental to 'difference' and communicating acceptance and respect, examining their own cultural prejudice and bias towards other cultures' p. 97. Lubimir \& Wen (2011) endorse this view, arguing that professionals should adopt attitudes of cultural humility and respect the individual beliefs and needs of service users. 


\section{Identify the antecedents and consequences of the concept}

Rodgers (1989) recommends that the antecedents and the consequences of the concept are evaluated. In respect of the antecedent literature there is evidence of commitment from members of the healthcare workforce to gain sufficient knowledge about cultural practices and religious beliefs so that the needs of people from minority ethnic cultures can be met. This is particularly evident in the grey literature which focuses on nursing adults with cancer and end of life care for elderly patients from Muslim, Hindu and Sikh faiths (Together for Short Lives and Marie Curie Cancer Care 2012). However, it would appear that when the professional development of clinical staff and carers neglects to acknowledge the importance of culture in the broader lives of people, there may be a risk of stereotyping. Studies that evaluate service-users as experts in defining and planning culturally-competent care appear to be absent in the literature.

\section{Identify Related Concepts}

Johnson et al. (2013) note how the concept of cultural competence relates to the holistic care of patients and their families in much of the literature. Notwithstanding, Paez et al. (2008) caution that definitions of cultural competence and how cultural competence is perceived in practice, is likely to differ according to the structure of organizations and the services provided. A scrutiny of the literature for this concept analysis has revealed a multiplicity of terminology (Table 4).

\section{Model Case}

Walker and Avant (2011) define a Model Case as a real-life illustration of the use of the concept that incorporates the attributes of the concept. The same authors advise that a Model Case should be identified in practice rather than constructed. The Model case below provides an example of cultural competency in a paediatric setting. 
Rabar was an 18 year-old young man diagnosed with Duchenne Muscular Dystrophy. He was the eldest child born into a Muslim family and had two younger sisters. Rabar and his family had received support from the organisation from his diagnosis and Rabar had enjoyed short-break care at the organisation for a number of years. An Advanced Care Plan had been discussed by staff with Rabar and his family and his Short-Stay Care Plan had been regularly updated at each visit. The young man's condition deteriorated suddenly during a routine short-break stay. The Charge Nurse informed the family, the Head Nurse on call and the Medical Director that Rabar's condition was giving cause for concern.

Rabar and his parents had previously agreed that they did not want aggressive intervention should his health deteriorate suddenly.

The Charge Nurse checked the record of Rabar's family wishes and aligned the head of his bed with an arrow set into the window sill tiles indicating the south easterly direction of Mekkah. She stayed close to Rabar providing comfort care and reassuring him verbally. The Charge Nurse 'phoned the Family and Transition Support Worker responsible for Rabar and his family and informed them of the situation. The Family and Transition Support Worker met the family when they arrived and reassured Rabar's parents that staff would be at hand to support the family in any way they wanted. Rabar's family stayed with him until after his death. During this time staff were close to hand but unobtrusive. They were able to answer any questions the family had, provide a copy of the Qur'an and prayer carpets from the religious artefacts cupboard and give the family refreshments. After his son's death, staff provided Rabar's father with washing facilities and the family were given a telephone so they could speak with relatives and begin to make funeral arrangements.

This Model Case demonstrates that staff were open to cultural diversity and communicated respect in fulfilling family wishes. Staff had worked with the young man and with individual family members to help them receive culturally appropriate end of life care. There was good 
dialogue between staff and service-users but staff respected the family's need for privacy while working effectively in terms of cultural awareness, knowledge, sensitivity and skills.

\section{Discussion}

UK and European legislation requires that people should receive holistic, culturally appropriate, sensitive palliative care (Department of Health 2008, Research Councils UK 2009, Kofman \& Lukes 2012). Undertaking the concept analysis has demonstrated that the concept of culturally- competent care is complex, multi-faceted and often expressed nondirectly in the literature which has resulted in a lack of consensus in relation to the concept. In healthcare practice, culturally competent care has aimed to improve care quality (Mead \& Bower 2000, Gregg \& Saha 2006, Saha et al. 2010). Notwithstanding, the literature examined demonstrates ambiguity in relation to the use of the concept across healthcare settings and other disciplines. Authors generally refer to the concept of culturally competent care as pivotal to patient care. However in the literature cultural competence is generally regarded as comprising just one aspect of holistic care.

Culturally-competent care should include structures and processes designed to enhance the quality of patient experience and healthcare outcomes. Although training in cultural competence is a recurrent recommendation in the literature examined, there appears to be little by way of suggestion as to the components of professional training. It has become apparent that healthcare staff and healthcare providers need to develop knowledge and skills which are embedded in their practice. This demands that the concept of cultural care is perceived and understood as universally integral to holistic patient care, irrespective of a person's race or ethnicity.

\section{Limitations}

This paper aimed to clarify the concepts 'culture' and the construct of 'culturally-competent care' in relation to the palliative care needs of young people from South Asian cultures. Notwithstanding there are limitations. Firstly, the relative paucity of literature from a 
theoretical perspective meant that the majority of the literature reviewed relied on empirical studies. Secondly, the attributes or clusters of characteristics used in the literature in relation to 'culture' and 'culturally-competent care' are diverse and often used interchangeably, making it difficult to achieve coherence of meaning. Thirdly, palliative care for young people has only emerged as a speciality in recent decades owing to advances in medicine and science and children with life-limiting condition surviving longer. Therefore most of the literature reviewed focussed on adults with no sound evidence-base as to how the cultural needs of young people might be best met.

\section{Conclusion}

Berntsson et al. (2007) have advocated that there is greater likelihood for young people with long-term illness or disabilities to experience holistic well-being when they are 'integrated in society' p.424). Young people with life-limiting and life-threatening conditions rely on palliative care services and the palliative care workforce to provide them with care that meets their individual needs and enables them to continue living their lives according to their choice. However, studies that evaluate service-users as experts in defining and planning cultural care appear to be absent in the literature. Thus, if Rodger's (1989) model of concept analysis is utilised, it could be argued that in reality antecedents and consequences of culturally- competent care although defined, may not be present in practice and are, in fact still evolving.

The literature has revealed that in spite of acknowledging people's rights to high quality end of life care, members of BAME cultures may be particularly vulnerable to inequalities. There is an urgent need to develop a robust tool to assess cultural competency in practice in order to achieve high quality holistic palliative care, appropriate to the spiritual, cultural and religious needs of young people and their families from BAME cultures.

Funding: This research received no specific grant from any funding agency in the public, commercial or not profit sectors. 
Conflict Statement: No conflict of interest has been declared by the authors.

Author Contributions: All authors have agreed on the final version and meet at least one of the following criteria (Recommended by the ICMJE (http://www.icmje.org/recommendations/)

- Substantial contributions to conception and design, acquisition of data, or analysis and interpretation of data;

- Drafting the article or revising it critically for important intellectual content. 


\section{References}

Ali Z., Fazil Q., Bywaters P., Wallace L. \& Singh G. (2001) Disability, Ethnicity and Childhood: a critical review of research. Disability and Society 16 (7), 949-68.

Archer M.S. (1985) Global Culture, Nationalism, Globalization and Modernity. (1985) SAGE, London.

Baldwin M.A. \& Rose P. (2009) Concept Analysis as a Dissertation Methodology. Nurse Education Today 29 (7), 780-83. doi: 10.1016/j.nedt.2009.03.009.

Baggerley J. \& Abugideiri S. (2010) Grief counselling for Muslim pre-school and elementary children. Journal of Multicultural Counselling and Development 38, 112-24.

doi:10.1002/j.2161-1912.2010.tb00119.x/pdf

Barzansky B., Jonas H.S. \& Etzel S.I. (2000) Educational Programs in U.S. Medical Schools. Journal of American Medical Association 284 (9), 1114 - 20.

Beach M.C., Price E.G., Gary T.L., Robinson, K.A., Aysegul G., Palacio A., Smarth C., Jenckes M.W., Feuerstein C., Bass E., Powe N.R. \& Cooper L.A. (2005), Cultural competency: a systematic review of Health Provider Educational Interventions. Medical Care 43 (4), 356-73.

Berntsson L., Berg M., Brydolf M. \& Hellstrom A. (2007) Adolescents' experiences of wellbeing when living with a long-term illness or disability. Scandinavian Journal of Caring Sciences 10, 419-25.

Brown E. (2007) Supporting the Child and the Family in Paediatric Palliative Care. David Fulton, London.

Brown E., Patel R., Kaur J. \& Coad J. (2013) The Interface between South Asian Culture and Palliative Care for Children, Young People and Families - a discussion paper. Issues in Comprehensive Nursing 36 (1-2), 120-43.

Butt J. \& Mirza K. (1966) Social Care and Black Communities. London, Race Equality Unit.

Carter B., Coad J., Bray B., Goodenough T., Moore A., Anderson C. \& Widdas D. (2012) Home-based care for special healthcare needs - Community nursing services. Nursing Research 61, 260-68. doi: 10.1097/NNR.0b013e31825b6848.

Chamba R. \& Jones L. (2000) Education of Asian deaf children. In: S. Gregory, P. Knight, W. McCrockan, S. Powers \& L. Watson, (eds.) Literacy in the homes of young deaf children: common and distinct features of spoken language and sign bilingual environments. David Fulton, London

Chand A. \& Thoburn J. (2010) Research review: Child and Family Support Services with Minority Ethnic Families: what can we learn from the research? Child and Family Social Work 10, 88-89.

Coad J.E. (2002) An Investigation of the Impact on the Nurse Lecturer of the Transfer of Nurse Education into Higher Education. PhD Thesis, University Wolverhampton. 
Constantine M.G. \& Ladany N. (2001) New visions for defining and assessing multi-cultural counselling competence. In: Ponterotte J.G., Casas J.M., Suzuki L.A. \& Alexander C.M. (eds.) Handbook of Multicultural Counselling. (2 ${ }^{\text {nd }}$ edition) SAGE, California. 482-98.

Department of Health (2008) The UK National End of Life Care Strategy - Promoting high quality care of all adults at the end of their life. Department of Health, London

Equalities National Council and Scope (2012) Over-looked Communities, Over-due Change: how services can better support BME disabled people. Equalities National Council and Scope, London.

EunYoung S. (2004) The Model of Cultural Competence through an Evolutionary Concept Analysis. Journal of Transcultural Nursing 15 (2), 93-102. doi: 10.1177/1043659603262488

Fazil Q., Wallace L., Sing G., Ali Z. \& Bywaters P. (2004) Empowerment and advocacy: reflections on action research with Bangladeshi and Pakistani families who have children with severe disabilities. Health and Social Care in the Community 12 (5), 389-97.

Fraser L., Fleming T., Miller M., Draper E., Mc Kinney P. \& Parslow R. (2012) Rising national prevalence of life-limiting conditions in children in England. Pediatrics 129, 1-7.

Gregg, J. \& Saha, S. (2006) Losing culture on the way to competence: The use and misuse of culture in medical education. Academic Medicine 81, 542-47.

George J.B. (2011) Nursing theories: the base for professional nursing practice. (6 $6^{\text {th }}$ edition) Prentice Hall, New Jersey.

Harriss K. \& Salway S. (2009) 'Long-term ill-health, poverty and ethnicity'. Ethnicity and Inequalities in Health and Social Care 2 (3), 39 - 48.

Helman C.G. (2000) Doctor-patient interaction. In C.G. Helman (ed.) Culture, Health and Illness. Butterworth Heineman, Boston. p.170-201.

Hutchinson T. (2011) Whole person care: A new paradigm for the $21^{\text {st }}$ century. Springer, New York.

Institute of Race Relations (2015) Poverty Statistics.

http://www.irr.org.uk/research/statistics/poverty accessed 1/11/2015.

Johnson G., Vukle A. \& Parker S. (2013) Cultural understanding in the provision of supportive and palliative care: perspectives in relation to the indigenous population. British Medical Journal Supportive and Palliative Care 3, 61-68.

Kofman E. \& Lukes S. (2012) The equality implications of being migrant in Britain. Research Report, 19. Equality and Human Rights Commission, London.

Kumas Tan Z., Beagan B., Loppie C., McLeod A., \& Blye F. (2007) Measures of Cultural Competence: Examining Hidden Assumptions. Academic Medicine 82 (6), 548-57.

Lubimir K. \& Wen A. (2011) Towards Cultural Competency in End of Life Communication Training. Hawai'i Medical Journal 70 (11), 239-41. 
Manchaiah VK, Stephens D, \& Meredith R. (2011). The patient journey of adults with hearing impairment: the patients' views. Clinical Otolaryngology 36(3), 227-34. doi: 10.1111/j.17494486.2011.02320.x.

McWhinney I. (1989) The need for a transformed clinical method. In Stewart, M. and Roter, D. Communicating with Medical Patients. SAGE, London. p.p. 25-42

Mead N. \& Bower P. (2000) Patient-centeredness: a conceptual framework and review of the empirical literature. Society Science Medicine, 51, 1087-110.

Office for National Statistics (2012). Census 2011. Office for National Statistics, London. Available at https://www.ons.gov.uk

Owen, A. \& Randhawa G. (2004) 'It's different from my culture: they're very different': providing community-based, 'culturally competent' palliative care for South Asian people in the UK. Health and Social Care in the Community 12 (5), 414-21.

Paez K., Allen J.K., Carson K. \& Cooper L. (2008) Provider and clinic cultural competence in a primary care setting. Social Science and Medicine 66 1204-1216.

Parekh B. (2005) Rethinking Multiculturalism - Cultural Diversity and Political Theory. Harvard University Press, Harvard.

Research Councils UK (2009) Engaging in Europe. Research Councils U.K., Swindon.

Rodgers B.L. (1989) Concepts, analysis, and the development of nursing knowledge: The evolutionary cycle. Journal of Advanced Nursing 14 330-35.

Rodgers B.L. \& Knafl K.A. (2000) (2 ${ }^{\text {nd }}$ Edition) Concept Development in Nursing. Philadelphia, Saunders.

Robinson L. (2008) Cultural Identity and Acculturation Preferences Among South Asian Adolescents in Britain: an exploratory study. Children and Society 23, 442-54. doi: 10.1558/firn.v8i2.241

Saha S., Beach, M.C. \& Coope, L.A. (2010), Patient-Centeredness, Cultural Competence and Healthcare Quality. Journal National Medical Association 100 (11), 1275-85.

Shah R. (1995) The Silent Minority: Children with Disabilities in Asian Families. National Children's Bureau, London.

Street R., O'Malley K., Cooper L. \& Haider P. (2011) Understanding concordance in patientphysician relationships: personal and ethical dimensions of shared identity. Annals of Family Medicine 6, 198-205. doi: 10.1370/afm.821.

Taylor J. (2003) Confronting 'Culture' in Medicine's Culture of No Culture. Academic Medicine 78 (6), 555-59.

Taylor L.K., Miller M., Joffe T., Parslow R.C., Aldridge J., Baile, C.C. \& McKinney P.A. (2010) Palliative care in Yorkshire UK 1987-2008: survival and mortality in a hospice. Archives of Disease in Childhood 95, 89-93.

Together for Short Lives (2012) 'The Big Study for Life-limited Children and their Families.' Accessed on 20/11/14 www.togetherforshortlives.org.uk 
Together for Short Lives and Marie Curie Cancer Care (2012) Don't Let Me Down: ensuring a good transition for young people with palliative care needs. Together for Short Lives and Marie Curie Cancer Care, London.

Tucker C.M., Arthur T., Roncoroni J., Whitney Wall M.S. \& Sanchez J. (2013) PatientCentred, Culturally Sensitive Health Care. American Journal of Lifestyle Medicine 9 (1), 6377.doi: $10.1186 / 1475-9276-12-18$

Walker L. \& Avant K. (2011) Strategies for theory construction in nursing. New York, Prentice Hall.

Wilson B.M. (1969) Promoting compliance: the patient-provider partnership. Journal of Advance Renal Replacement Therapy 2 (3), 199-206. 
Table i): Coad's (2002) Six Step Approach

\begin{tabular}{|c|l|}
\hline 1. & Identify and name the concept of interest \\
\hline 2. & Identify surrogate terms and relevant uses of the concept \\
\hline 3. & Identify the attributes related to the concept \\
\hline 4. & Identify the references, antecedents and consequences of the concept \\
\hline 5. & Identify related concepts \\
\hline 6. & Identify a model case of the concept \\
\hline
\end{tabular}


Figure i) : Data search and selection process

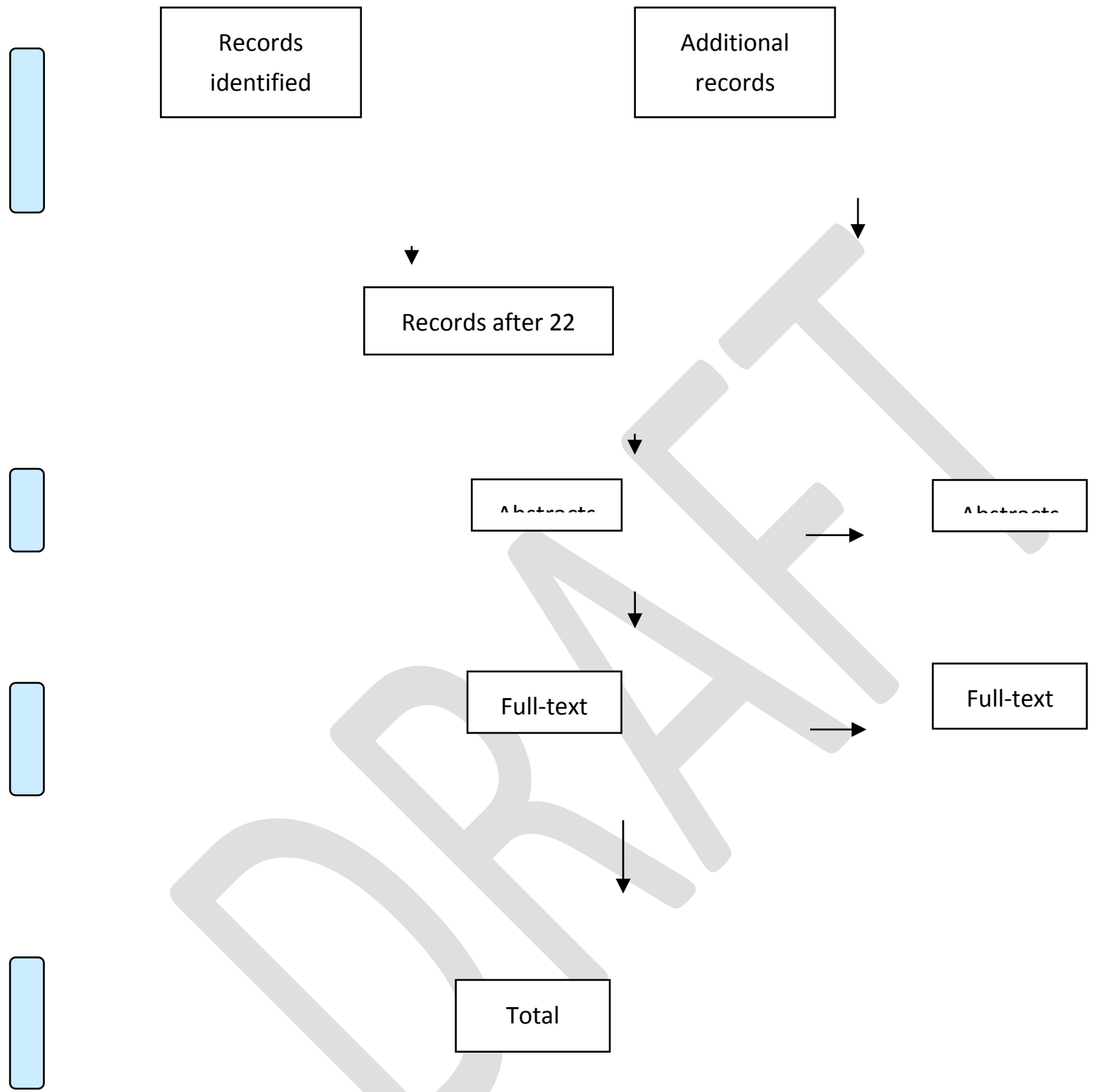




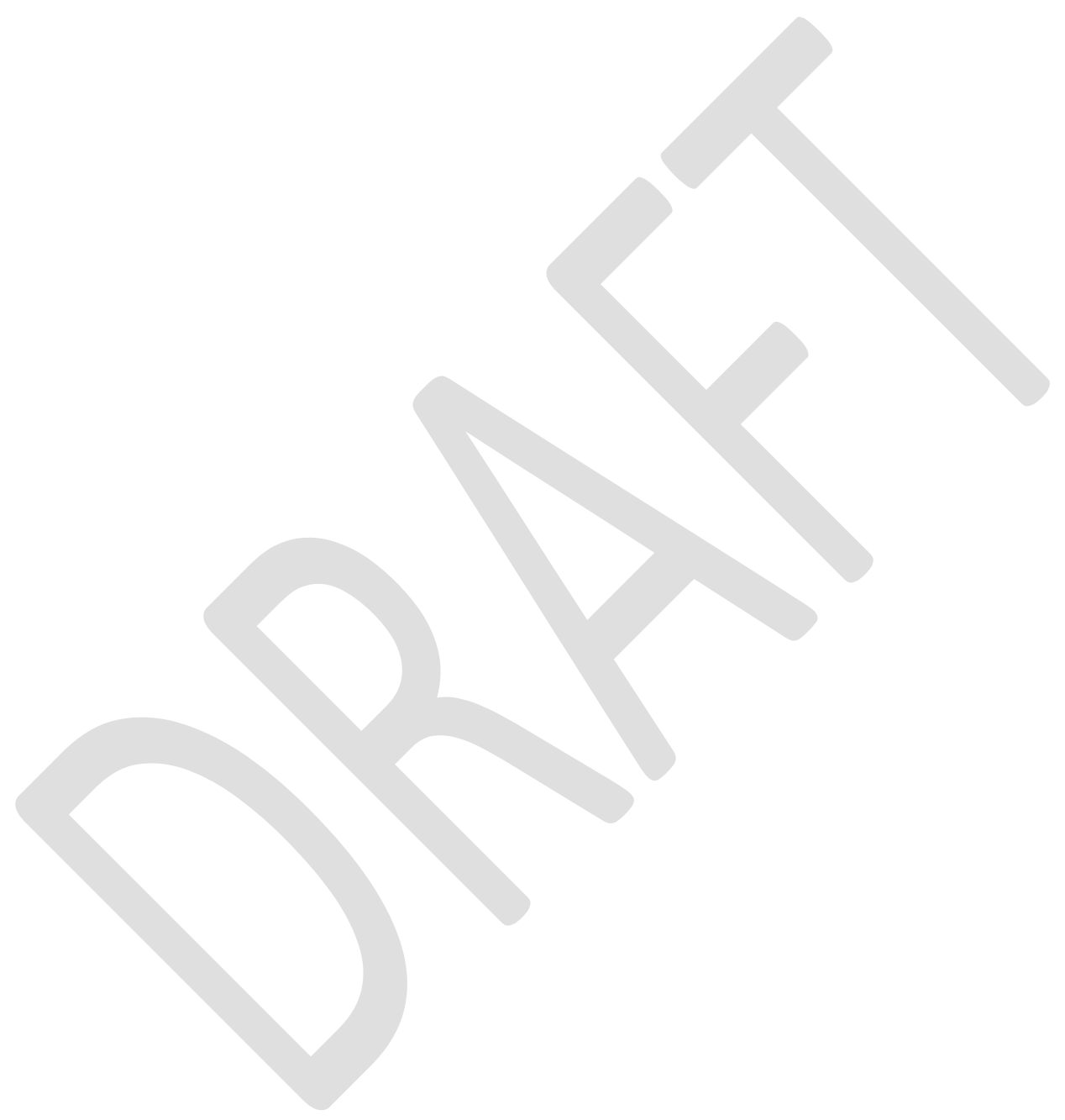


Figure ii) : Surrogate Terms for Culturally-Competent Care

Cultural sensitivity - Beach et al., (2005); Boyle \& Springer, (2001)

Understanding of cultural behaviour - Rudd \& Stack, (2006)

Anti-discriminatory practice - Owen \& Randhawa, (2004)

Cultural humility - Lubimir \& Wen, (2011); Boyle \&

Springer, 2001

Cultural understanding - Johnson et al., (2013)

Person-centred sensitive care - Tucker et al., (2013); Herman et al., (2007)

Professional-person centred relationship - Mead \& Bower, (2000)

Doctor-patient interaction - Levenstein et al., (1986)

Patient-centred approach - Saha et al., (2010)

Patient-provider partnership - Wilson, (1969)

Empathetic care - Rudd \& Stack, (2006)

Patient-meaningful care - Johnson et al., (2013)

Culturally responsive care - Tucker et al., (2013) 
Figure iii) : Identified related concepts

Anti-discriminatory practice, Owens \& Randhawa, (2004)

Culturally sensitive care, Beach et al., (2005); Tucker et al., (2013); Saha et al., (2010)

Transcultural Care, Beach et al., (2005)

Cross-cultural care, Paez, (2008)

Culturally diverse care, Kumas-Tan et al., (2007); Paez et al., (2008)

Cultural centeredness, Tucker et al., (2013)

Cultural confidence, Merriam-Webster dictionary, (2003).

Cultural humility, Lubimir \& Wen, (2011)

Cultural understanding, Johnson et al., (2013)

Culturally compassionate care, Evans et al., (2012) 